\title{
The effects of a specific growth hormone antagonist on overnight insulin requirements and insulin sensitivity in young adults with Type 1 diabetes mellitus
}

\author{
R. M. Williams ${ }^{1}$, R. Amin 1 , F. Shojaee-Moradie ${ }^{2}$, A. M. Umpleby ${ }^{2}$, C. L. Acerini ${ }^{1}$, D. B. Dunger ${ }^{1}$ \\ ${ }^{1}$ University of Cambridge, Department of Paediatrics, Addenbrooke's Hospital, Cambridge, UK \\ ${ }^{2}$ Departments of Diabetes, Endocrinology and Metabolic Medicine, St Thomas's Hospital, London, UK
}

\begin{abstract}
Aims/hypothesis. Growth hormone hypersecretion in Type 1 diabetes could exacerbate insulin resistance and contribute to declining glycaemic control. Our aim was to determine the effects of specific growth hormone blockade on insulin sensitivity and lipolysis in young adults with Type 1 diabetes.

Methods. We studied the effects of two doses of a specific growth hormone antagonist (B2036-PEG; Somavert, Pharmacia Corporation, Milton Keynes, UK) on insulin sensitivity in seven young adults (17-22 yrs, $3 \mathrm{M})$ with Type 1 diabetes. Subjects recieved 5 and $10 \mathrm{mg}$ B2036-PEG, in random order for 3 weeks, with a 3-week washout. At baseline and following each treatment block, an overnight (03:00 to 08:00 h) insulin infusion for euglycaemia $(5 \mathrm{mmol} / \mathrm{l})$, followed by two-step hyperinsulinaemic euglycaemic clamp, using $\left[6,6{ }^{2} \mathrm{H}_{2}\right]$ glucose and ${ }^{2} \mathrm{H}_{5}$ glycerol to measure glucose and glycerol turnover was performed.

Results. Compared to baseline, overnight insulin requirements decreased with both doses: (means \pm SEM)
\end{abstract}

$0.34 \pm 0.02 \mathrm{mU} / \mathrm{Kg} / \mathrm{min}$ vs $0.25 \pm 0.01(5 \mathrm{mg})(p=0.04)$, and $0.24 \pm 0.01(10 \mathrm{mg})(p=0.004)$. IGF-I $(\mathrm{ng} / \mathrm{ml}) \mathrm{de}-$ creased following $10 \mathrm{mg}[223.5 \pm 23.9$ vs $154.6 \pm 28.1$ $(p=0.005]$, but not $5 \mathrm{mg}$. Mean overnight non esterified fatty acid concentrations $(\mathrm{mmol} / \mathrm{l})$ decreased with $10 \mathrm{mg}[0.51 \pm 0.04$ vs $0.38 \pm 0.04 \quad(p=0.03)]$, as $\mathrm{did}$ $\beta$-hydroxybutyrate (mmol/l); $[0.31 \pm 0.04$ vs $0.15 \pm 0.02$ $(p=0.004)]$. Glycerol production rate, an index of lipolysis, was lower following $10 \mathrm{mg}(p=0.04)$, but insulin sensitivity during the clamp did not change with either dose.

Conclusion/interpretation. Treatment with both doses of B2036-PEG reduced overnight insulin requirements. The $10 \mathrm{mg}$ dose suppressed lipolysis and reduced IGF-I. Failure to show enhanced insulin sensitivity during the clamp with the $10 \mathrm{mg}$ dose could reflect opposing actions of growth hormone and IGF-I. [Diabetologia (2003) 46:1203-1210]

Keywords Type 1 diabetes mellitus, B2036-PEG, growth hormone antagonist, insulin sensitivity, lipolysis.

Received: 5 May 2003 / Revised: 2 June 2003

Published online: 24 July 2003

(C) Springer-Verlag 2003

Corresponding author: Prof. D. B. Dunger, University of Cambridge, Department of Paediatrics, Box 116, Addenbrooke's Hospital, Hills Rd, Cambridge, UK

E-mail:dbd25@cam.ac.uk

Abbreviations: T1DM, Type 1 diabetes mellitus; GH, growth hormone; IGF-I, insulin-like growth factor 1; IGFBP-1, IGF binding protein 1; IGFBP-3, IGF binding protein 3; NEFA, non eosterified fatty acids; $\beta \mathrm{OHB}, \beta$-hydroxybutyrate.

Young adults with Type 1 diabetes mellitus (T1DM) have higher concentrations of circulating growth hormone $(\mathrm{GH})$ than age-, sex- and puberty-matched controls without diabetes [1]. There are increased basal GH concentrations, as well as increased amplitude and frequency of $\mathrm{GH}$ pulses overnight [2]. In addition to this spontaneous GH hypersecretion, there is an exaggerated response to a variety of $\mathrm{GH}$ provocation tests $[3,4,5,6,7]$. There is also a failure of the normal suppression of GH secretion by hyperglycaemia $[6,8]$. One explanation for the $\mathrm{GH}$ hypersecretion seen in young people with diabetes is that low concentrations 
of insulin within the portal circulation subsequently lead to reduced concentrations of circulating IGF-I, resulting in a negative feedback drive effect at the pituitary gland and subsequent GH hypersecretion [9].

$\mathrm{GH}$ affects glucose metabolism, leading to increased insulin resistance, which could either be direct or mediated by increased concentrations of circulating free fatty acids following stimulation of lipolysis [10, 11]. GH exerts its maximal effects on insulin sensitivity 5 to $6 \mathrm{~h}$ after a pulse of GH [10]. In subjects with T1DM, overnight GH secretion peaks at approximately 01:00 h leading to increased insulin requirements in the early morning, and fasting hyperglycaemia; the socalled dawn phenomenon [12].

Suppression of the actions of $\mathrm{GH}$ has been explored as a potential adjunct to insulin therapy in T1DM. Studies using the long-acting somatostatin analogue; octreotide have demonstrated insulin sensitivity and increased reductions in hyperglycaemia throughout the day $[13,14,15,16]$. However, although octreotide does suppress GH secretion, it also has a wide spectrum of other effects, which makes it difficult to determine the precise contributions of different hormones to alterations in insulin sensitivity. Short-term studies using the anti-cholinergic agent pirenzipine have also shown effective suppression of GH secretion, with enhancement of insulin sensitivity $[17,18]$. However, the short half-life of pirenzipine limits its efficacy and benefits were not sustained in longer studies, with attempts to prolong its half-life leading to an exacerbation of side effects.

The use of exogenous recombinant human IGF-I (rhIGF-I) to suppress GH secretion has been considered as a physiological approach to therapy in T1DM [19]. Studies using replacement doses of rhIGF-I showed improvements in glycaemic control over periods of up to 6 months when given as co-therapy with insulin [20, 21]. However, it is difficult to ascertain the precise role of $\mathrm{GH}$ in modulating insulin sensitivity when using rhIGF-I to suppress endogenous GH secretion, as IGF-I itself enhances insulin sensitivity [22].

B2036-PEG is a specific GH antagonist (Pegvisomant, Somavert, Pharmacia, Milton Keynes, UK), which binds to the extracellular domain of the GH receptor, but disrupts its dimerisation and subsequent downstream signalling, leading to reductions in the concentration of circulating IGF-I [23]. We have studied the effects of two doses of B2036-PEG in adolescents with T1DM on circulating IGF-I concentrations, overnight insulin requirements for euglycaemia, insulin sensitivity and lipolysis in an attempt to ascertain whether enhancement of insulin sensitivity by the direct blockade of GH can be achieved with or without reductions in IGF-I and whether these effects are mediated by an effect on lipolysis.

\section{Subjects and methods}

Subjects. We recruited seven young adult subjects with T1DM to the study [three males, median age 18.7 years (range 17.3 to 22.6); median BMI $26.7 \mathrm{Kg} / \mathrm{m}^{2}$ (range 22.2 to 28.2); median $\mathrm{HbA}_{1 \mathrm{c}}$ 9.4\% (range 8.0-10.5)]. All were post pubertal, with T1DM of at least 2 years' duration, and C-peptide negative. All had normal renal, hepatic and thyroid function and a normal full blood count. None had any evidence of microalbuminuria or retinopathy. All were treated with a combination of short and long acting insulins two to four times per day [median insulin dose $0.9 \mathrm{u} / \mathrm{Kg} / 24 \mathrm{hrs}$ (range 0.5-1.1)]. The study protocol was approved by the Cambridge, Aylesbury and Northampton Local Research Ethics Committees. Written, informed consent was obtained from all subjects prior to the study. All overnight studies were carried out in the Wellcome Trust Clinical Research Facility at Addenbrooke's Hospital, Cambridge, UK.

Study design. The study was an investigator blinded, randomised crossover study of two 3-week treatment periods with either 5 or $10 \mathrm{mg}$ B2036-PEG S5 and S10 respectively, administered once daily via subcutaneous injection, separated by a 3-week washout period (Fig. 1).

In order to minimise the risk of hypoglycaemia, on commencement of treatment with B2036-PEG, subjects were advised that they might need to reduce their insulin dose by 15 to $20 \%$. Subsequently, the insulin dose was titrated according to home glucose monitoring; subjects were advised to carry out four to five fingerprick blood glucose measurements daily.

Following a run in period a baseline study of overnight insulin requirements and insulin sensitivity was carried out. This was repeated at the end of each treatment block. $36 \mathrm{~h}$ preceding each study period, all intermediate and long-acting insulin was withdrawn. During this time, blood glucose was controlled with multiple daily injections of soluble insulin, with the last injection being given between 12:00 $\mathrm{h}$ and 13:00 $\mathrm{h}$ on the day of the study. Subjects were admitted to the investigation ward at 17:00 $\mathrm{h}$ and two intravenous cannulae were sited; one for blood sampling and one for the infusion of intravenous fluids. A standardised meal was given at 18:00 $\mathrm{h}$ and subjects were then fasted until 12:00 $\mathrm{h}$ the next day.

Between 18:00 $\mathrm{h}$ and 08:00 h, a variable rate insulin infusion was administered. Blood glucose was determined every $15 \mathrm{~min}$ and the insulin infusion rate adjusted to maintain blood glucose at $5 \mathrm{mmol} / \mathrm{l}$ : no glucose was administered during this period.

Between 08:00 $\mathrm{h}$ and 12:00 $\mathrm{h}$ the following morning, a two-step hyperinsulinaemic euglycaemic clamp study was carried out. At $05: 00 \mathrm{~h}$ primed infusions $\left(\left[6,6{ }^{2} \mathrm{H}_{2}\right]\right.$ glucose, $170 \mathrm{mg}$ intravenous bolus followed by continuous infusion, $1.7 \mathrm{mg} / \mathrm{min}$ and ${ }^{2} \mathrm{H}_{5}$ glycerol, $0.61 \mathrm{mg} / \mathrm{Kg}$ bolus followed by $0.15 \mathrm{mg} / \mathrm{kg} / \mathrm{min}$ continuous infusion) were commenced and continued for the duration of the study. A two-step hyperinsulinaemic euglycaemic clamp was done between 08:00 h and 10:00 h, (step one, 08:00 h-10:00 h, insulin bolus $3.5 \mathrm{mU} / \mathrm{Kg}$ followed by infusion $0.75 \mathrm{mU} / \mathrm{Kg} / \mathrm{min}$; step two,

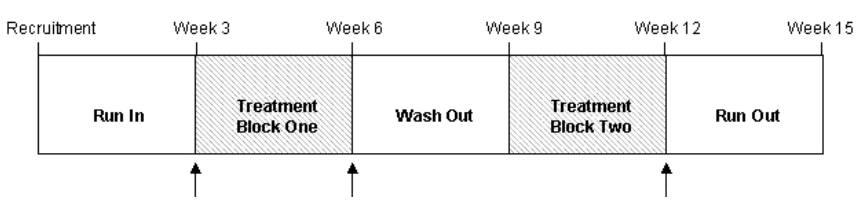

Fig. 1. Pictorial representation of study schedule. Arrows denote timing of overnight variable rate insulin infusion and twostep hypernisulinaemic euglycaemic clamp study 
10:00 h-12:00 h, insulin bolus $7 \mathrm{mU} / \mathrm{Kg}$ followed by infusion $1.5 \mathrm{mU} / \mathrm{Kg} / \mathrm{min})$. During the hyperinsulinaemic clamp, blood glucose was determined every $5 \mathrm{~min}$ and maintained at $5 \mathrm{mmol} / \mathrm{l}$ using a variable rate $20 \%$ dextrose infusion. The $20 \%$ dextrose was enriched with $7 \mathrm{mg}\left[6.6{ }^{2} \mathrm{H}_{2}\right]$ glucose to prevent marked decreases in blood tracer enrichment and consequent calculation errors. Serum enrichment of $\left[6.6{ }^{2} \mathrm{H}_{2}\right]$ glucose and ${ }^{2} \mathrm{H}_{5}$ glycerol were determined every 5 min during each steady state period (baseline 07:30 h to 08:00 h; step one, 09:30 h to 10:00 $\mathrm{h}$ and step two, 11:30 $\mathrm{h}$ to $12: 00 \mathrm{~h})$.

Throughout the study period (18:00 h to $12: 00 \mathrm{~h}$ ), blood samples were taken regularly for determination of plasma-free insulin (30 min), IGFBP-1, $\beta$-hydroxybutyrate and serum NEFA (60 min). A fasting blood sample was collected at 08:00 h for plasma IGF-I and IGFBP-3 determination. Subjects remained supine throughout the study period and had similar sleep patterns during each night of observation.

Assays. Blood glucose concentrations were measured using $25 \mu \mathrm{l}$ whole blood samples on a Y.S.I. model 2300 stat plus analyser (Yellow Springs Instruments, Analytical Technologies, Farnborough, Hampshire, UK). Plasma samples for determination of insulin concentration were collected into $25 \%$ polyethylene glycol and measured by ELISA, using a commercial kit (DSL, Tooting, London) according to the manufacturer's instructions. The sensitivity of this assay was $0.26 \mathrm{mU} / \mathrm{l}$. Intraassay imprecision (CV) was $4.4 \%$ at $10.3 \mathrm{mU} / \mathrm{l}$ and $5.1 \%$ at $35.8 \mathrm{mU} / \mathrm{l}$. Equivalent inter-assay imprecision was, $8.7 \%$ and $2.9 \%$ respectively. Plasma (total) IGF-1 concentrations were measured in ethanolic extracts by ELISA, (DSL, Tooting, London, UK). The sensitivity of this assay was $0.03 \mathrm{ng} / \mathrm{ml}$. Intraassay imprecision (CV) was $8.8 \%$ and $9.4 \%$ at 107 and $262 \mathrm{ng} / \mathrm{ml}$ respectively. Equivalent inter-assay imprecision (CV) was $6.1 \%$ and $8.0 \%$ at 107 and $262 \mathrm{ng} / \mathrm{ml}$ respectively, respectively. Plasma (total) IGFBP-1 concentrations were measured by ELISA, (DSL). The sensitivity of this assay was $0.25 \mathrm{ng} / \mathrm{ml}$. Intra-assay imprecision (CV) was $6.1 \%$ at $7.0 \mathrm{ng} / \mathrm{ml}$ and $5.3 \%$ at $48.4 \mathrm{ng} / \mathrm{ml}$. Equivalent inter-assay imprecision was, $10.4 \%$ and $5.1 \%$ respectively. Plasma IGFBP-3 concentrations were measured by ELISA (DSL). The sensitivity of this assay was $0.04 \mathrm{ng} / \mathrm{mL}$. Intra-assay imprecision (CV) was $4.9 \%$ and $2.8 \%$ at 5.2 and $34.7 \mathrm{ng} / \mathrm{ml}$ respectively. Equivalent inter-assay imprecision (CV) was $9.7 \%$ and $1.9 \%$ at 5.2 and $34.7 \mathrm{ng} / \mathrm{ml}$ respectively. We did not measure serum GH concentrations in this study due to theoretical cross-reactivity of Somavert with antibodies in standard assays, and we did not have access to a specific assay.

Plasma glycerol concentration was measured by a direct enzymatic colorimetric method (Randox Laboratories, Co. Antrim, UK), (inter assay CV 3.7\%) and NEFA was measured by an enzymatic colorimetric method (Wako chemicals, Neuss, Germany), (inter assay CV 3.6\%) using a Cobas Fara II autoanalyzer (Roche, Welwyn Garden City, UK). $\beta$-hydroxybutyric acid $(\beta \mathrm{OHB})$ was measured using a standard enzymatic technique (Sigma Diagnostics, $\beta$-hydroxybutyric acid kit, Poole, Dorset, UK).

Glucose and glycerol enrichment were measured by gas chromatography mass spectrometry (GC-MS) using a Hewlett Packard 5971A MSD (Agilent Technologies, Berks, UK). Glucose enrichment was determined from deproteinised plasma using the methoxime-trimethylsilyl ether derivative [24]. Glycerol was isolated from deproteinised plasma using ion exchange chromatography and glycerol enrichment was determined using the tris-trimethylsilyl derivative [25, 26]. GC-MS analysis used electron impact ionisation with selected ion monitoring of the ions at mass/charge ratio (m/z) 319 and 321 for glucose and 205 and 208 for glycerol.
Calculations. Metabolic clearance rate of insulin (MCR-I) was calculated overnight from the mean insulin infusion rate and mean plasma insulin concentrations during this period [27]. Glucose infusion rate $(\mathrm{mg} / \mathrm{Kg} / \mathrm{min})$ was determined during the final $30 \mathrm{~min}$ of both steps of the hyperinsulinaemic clamp from the mean rate of infusion of $20 \%$ dextrose required to maintain euglycaemia ( $5 \mathrm{mmol} / \mathrm{l}$ ) per $\mathrm{kg}$ body weight per min.

The enrichments of glucose and glycerol were expressed as the tracer/tracee ratio. The rates of appearance and disposal of glucose (glucose Ra and Rd respectively) and glycerol production rate (glycerol $\mathrm{Ra}$ ) were calculated using the Steele models for the non-steady state modified for use with stable isotopes $[28,29]$. The effective volume of distribution was assumed to be $143 \mathrm{ml} / \mathrm{kg}$ for glucose and $230 \mathrm{ml} / \mathrm{kg}$ for glycerol [29, 30, 31].

Statistics. Where data were normally distributed they were analysed using parametric tests. Serum insulin, IGFBP-1, IGFBP-3, $\beta \mathrm{OHB}$ were logarithmically transformed (base 10) to allow parametric testing. NEFA values were square root adjusted and glucose $\mathrm{Ra}$ and $\mathrm{Rd}$ and glycerol $\mathrm{Ra}$ values logarithmically transformed (base e) prior to analysis.

Repeated measures ANOVA was used to analyse the overnight steady state period of euglycaemia $(03: 00 \mathrm{~h}-08: 00 \mathrm{~h})$ during which time there was no change in blood glucose with time; nor any difference in blood glucose concentrations between the study nights.

Comparisons between means of the three study nights were made using Student's $t$ tests for paired samples, with each treatment period being compared with baseline. Differences in glucose and glycerol turnover were analysed using repeated measures ANOVA across time, with post hoc analysis (Dunnett's test for paired variables) to ascertain the effects of different doses of B2036-PEG. SPSS version 10 (SPSS, Chicago, Ill., USA) was used for all statistical analysis. A $p$ value of less than 0.05 (two-tailed) was considered statistically significant. Data are expressed as means \pm SEM unless otherwise stated.

\section{Results}

Randomisation. Four subjects $(2 \mathrm{M})$ received $\mathrm{S} 5$, and three (1M) S10 as their first block of treatment. There was no order effect observed and IGF-I concentrations returned to baseline after treatment 1 , prior to treatment 2, regardless of the order in which subjects received B2036-PEG; $[223.5 \pm 23.9 \mathrm{ng} / \mathrm{ml}$ before treatment block 1 and $238.0 \pm 30.1 \mathrm{ng} / \mathrm{ml}$ before treatment block $2(p=0.7)]$.

IGF-I and IGF binding proteins. Treatment with $5 \mathrm{mg}$ B2036-PEG tended to lower IGF-I concentrations but this did not reach statistical significance. Treatment with $\mathrm{S} 10$ led to a $30 \%$ reduction in IGF-I concentrations after 3 weeks of treatment (Table 1; $p=0.01$ ).

IGFBP-3 tended to be lower following treatment with B2036-PEG; $(3.0 \pm 1.2 \mathrm{mcg} / \mathrm{ml}$ at baseline vs $2.9 \pm 0.3$ following $S 5$ and $2.7 \pm 0.3$ following $\mathrm{S} 10$ ), however this did not reach statistical significance. Similarly, differences in the IGF-I/IGFBP-3 molar ratio following treatment with B2036-PEG $(0.48 \pm 0.05$ at baseline vs $0.39 \pm 0.05$ following S5 vs $0.39 \pm 0.08$ 
Table 1. Effects of B2036-PEG on fasting IGF-I and IGFBP-3 and overnight glucose and lipid metabolism

\begin{tabular}{|c|c|c|c|}
\hline & Pre-treatment & 5 mg B2036-PEG & 10 mg B2036-PEG \\
\hline \multicolumn{4}{|l|}{ Fasting bloods (08:00 h) } \\
\hline IGF-I (ng/ml) & $223.5 \pm 23.9$ & $183.8 \pm 38.1$ & $154.6 \pm 28.1 *$ \\
\hline IGFBP-3 $(\mathrm{mcg} / \mathrm{ml})$ & $3.01 \pm 0.1$ & $2.94 \pm 0.3$ & $2.69 \pm 0.3$ \\
\hline IGF-I/IGFBP-3 molar ratio & $0.48 \pm 0.05$ & $0.39 \pm 0.05$ & $0.39 \pm 0.08$ \\
\hline \multicolumn{4}{|c|}{ Overnight steady state period of euglycaemia (03:00-08:00 h) } \\
\hline Glucose $(\mathrm{mmol} / \mathrm{l})$ & $5.3 \pm 0.07$ & $5.1 \pm 0.04$ & $5.5 \pm 0.09$ \\
\hline Insulin requirement ( $\mathrm{mU} / \mathrm{Kg} / \mathrm{min})$ & $0.34 \pm 0.03$ & $0.25 \pm 0.01 *$ & $0.24 \pm 0.02 * *$ \\
\hline Plasma insulin (mU/l) & $21.8 \pm 2.4$ & $19.3 \pm 1.4$ & $18.3 \pm 1.6$ \\
\hline Insulin clearance rate $(\mathrm{ml} \cdot \mathrm{kg} / \mathrm{min})$ & $14.1 \pm 1.5$ & $14.2 \pm 1.1$ & $12.7 \pm 1.3$ \\
\hline $\mathrm{NEFA}(\mathrm{mmol} / \mathrm{l})$ & $0.51 \pm 0.04$ & $0.52 \pm 0.04$ & $0.38 \pm 0.04 *$ \\
\hline$\beta$-Hydroxybutyrate (mmol/l) & $0.31 \pm 0.04$ & $0.25 \pm 0.05$ & $0.15 \pm 0.02 * *$ \\
\hline IGFBP-1 (ng/ml) & $44.3 \pm 3.0$ & $56.6 \pm 3.7$ & $53.0 \pm 2.7$ \\
\hline
\end{tabular}

${ }^{*} p<0.05, * * p<0.005$ vs pre treatment

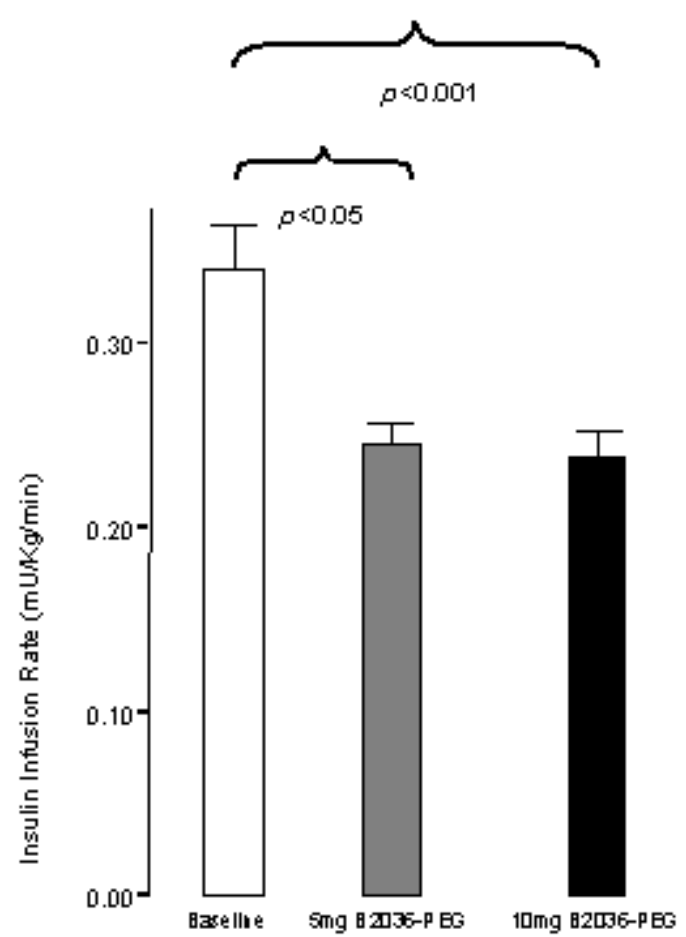

Fig. 2. Effects of B2036-PEG on overnight insulin requirements. Overnight (03:00-08:00 h) insulin requirements ( $\mathrm{mU} / \mathrm{Kg} / \mathrm{min}$ ) for euglycaemia $(5 \mathrm{mmol} / \mathrm{l})$ at baseline (white bar), following $5 \mathrm{mg}$ B2036-PEG (grey bar) and following 3 weeks 10 mg B2036-PEG (black bar)

following S10) were not significant $(p=0.09)$. No change was observed in IGFBP-1 concentrations following treatment with B2036-PEG (Table 1).

Overnight insulin requirement for euglycaemia. During the steady state period (03:00 h-08:00 h) for euglycaemia $(5 \mathrm{mmol} / \mathrm{l})$, there was no significant difference in blood glucose concentrations on the three study nights, but mean insulin infusion rates $(\mathrm{mU} / \mathrm{Kg} / \mathrm{min})$ were reduced following treatment with B2036-PEG $[0.35 \pm 0.03$ at baseline vs $0.25 \pm 0.01$

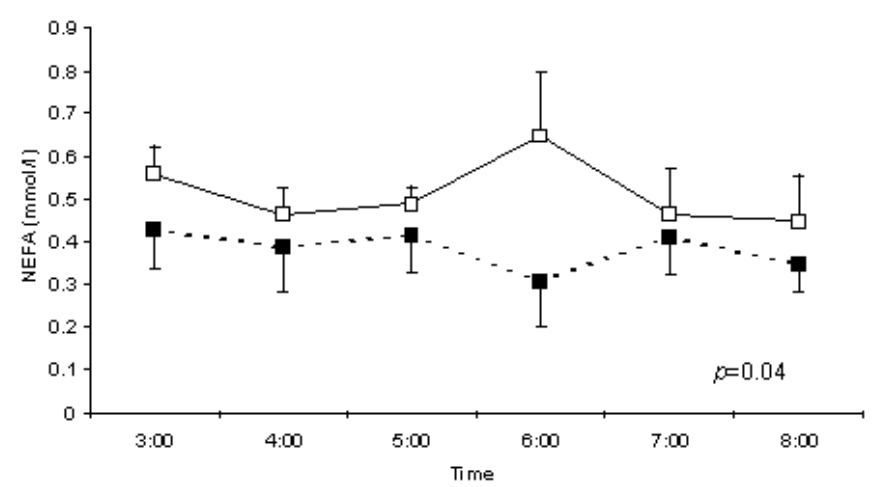

Fig. 3. Effects of B2036-PEG on overnight NEFA concentrations. Mean NEFA concentrations $(\mathrm{mmol} / \mathrm{l})$ during overnight (03:00-08:00 h) steady state euglycaemia $(5 \mathrm{mmol} / \mathrm{l})$ at baseline (white squares, solid line) and following 3 weeks of $10 \mathrm{mg}$ B2036-PEG (black squares, broken line). Error bars represent 1 SEM

( $p=0.02)$ following S5 and $0.24 \pm 0.01(p=0.004)$ following S10] (Fig. 2).

There were no differences in plasma-free insulin concentrations during steady state euglycaemia on the three study nights and although corresponding reductions in estimated insulin clearance were observed, they were not significant (Table 1).

Hyperinsulinaemic clamp. Glucose infusion rate for euglycaemia was not different during either step of the hyperinsulinaemic clamp following treatment with B2036-PEG. Neither glucose Ra, nor Rd were altered by treatment with either dose of B2036-PEG, either at baseline or during either step of the hyperinsulinaemic clamp (Table 2).

NEFA concentrations and glycerol production rate. Treatment with S10 led to a reduction in overnight NEFA concentrations overnight (Fig. 3, p<0.04) but not during the hyperinsulinaemic clamp (Table 2). Overnight mean $\beta \mathrm{OHB}$ concentrations were also 
Table 2. Effects of B2036-PEG on insulin sensitivity and lipid metabolism during the two-step hyperinsulinaemic clamp study. Baseline values were determined 07:30-08:00 h. Step one $(0.75 \mathrm{mU} / \mathrm{Kg} / \mathrm{min})$ was done from 08:00-10:00 $\mathrm{h}$ and step 2 (1.5 mU/Kg/min) from 10:00-12:00 h

\begin{tabular}{|c|c|c|c|c|}
\hline Hyperinsulinaemic clamp (08:00-12:00 h) & & Pre-treatment & 5 mg B2036-PEG & 10 mg B2036-PEG \\
\hline Glucose (mmol/l) & $\begin{array}{l}\text { Step one } \\
\text { Step two }\end{array}$ & $\begin{array}{l}4.9 \pm 0.02 \\
5.0 \pm 0.06\end{array}$ & $\begin{array}{l}5.0 \pm 0.03 \\
5.0 \pm 0.06\end{array}$ & $\begin{array}{l}4.9 \pm 0.03 \\
4.9 \pm 0.04\end{array}$ \\
\hline Plasma insulin (mU/l) & $\begin{array}{l}\text { Step one } \\
\text { Step two }\end{array}$ & $\begin{array}{l}54.4 \pm 4.4 \\
97.9 \pm 5.3\end{array}$ & $\begin{array}{l}43.8 \pm 5.9 \\
98.4 \pm 12.6\end{array}$ & $\begin{array}{r}53.1 \pm 4.6 \\
107.4 \pm 7.2\end{array}$ \\
\hline Glucose infusion rate (mg/kg/min) & $\begin{array}{l}\text { Step one } \\
\text { Step two }\end{array}$ & $\begin{array}{l}3.0 \pm 0.4 \\
7.9 \pm 0.6\end{array}$ & $\begin{array}{l}2.6 \pm 0.3 \\
7.0 \pm 0.9\end{array}$ & $\begin{array}{l}3.1 \pm 0.5 \\
7.8 \pm 0.7\end{array}$ \\
\hline Glucose $\mathrm{Ra}(\mu \mathrm{mol} / \mathrm{Kg} / \mathrm{min})$ & $\begin{array}{l}\text { Baseline } \\
\text { Step one } \\
\text { Step two }\end{array}$ & $\begin{array}{l}9.6 \pm 1.6 \\
4.1 \pm 0.9 \\
2.8 \pm 1.8\end{array}$ & $\begin{array}{l}9.8 \pm 0.8 \\
3.6 \pm 0.6 \\
2.1 \pm 0.7\end{array}$ & $\begin{array}{l}8.5 \pm 1.3 \\
2.6 \pm 0.9 \\
2.1 \pm 2.3\end{array}$ \\
\hline Glucose Rd ( $\mu \mathrm{mol} / \mathrm{Kg} / \mathrm{min})$ & $\begin{array}{l}\text { Baseline } \\
\text { Step one } \\
\text { Step two }\end{array}$ & $\begin{array}{r}9.2 \pm 1.3 \\
22.1 \pm 2.8 \\
50.1 \pm 4.6\end{array}$ & $\begin{array}{l}10.2 \pm 0.7 \\
18.9 \pm 2.1 \\
42.1 \pm 5.1\end{array}$ & $\begin{array}{r}9.7 \pm 1.0 \\
22.1 \pm 3.7 \\
46.1 \pm 6.8\end{array}$ \\
\hline NEFA (mmol/l) & $\begin{array}{l}\text { Step two } \\
\text { Step one } \\
\text { Step two }\end{array}$ & $\begin{array}{c}1.1 \pm 0.3 \\
0.21 \pm 0.05 \\
0.04 \pm 0.01\end{array}$ & $\begin{array}{c}2.4 \pm 0.5 \\
0.26 \pm 0.04 \\
0.07 \pm 0.03\end{array}$ & $\begin{array}{c}1.4 \pm 0.2 \\
0.16 \pm 0.02 \\
0.02 \pm 0.00\end{array}$ \\
\hline
\end{tabular}

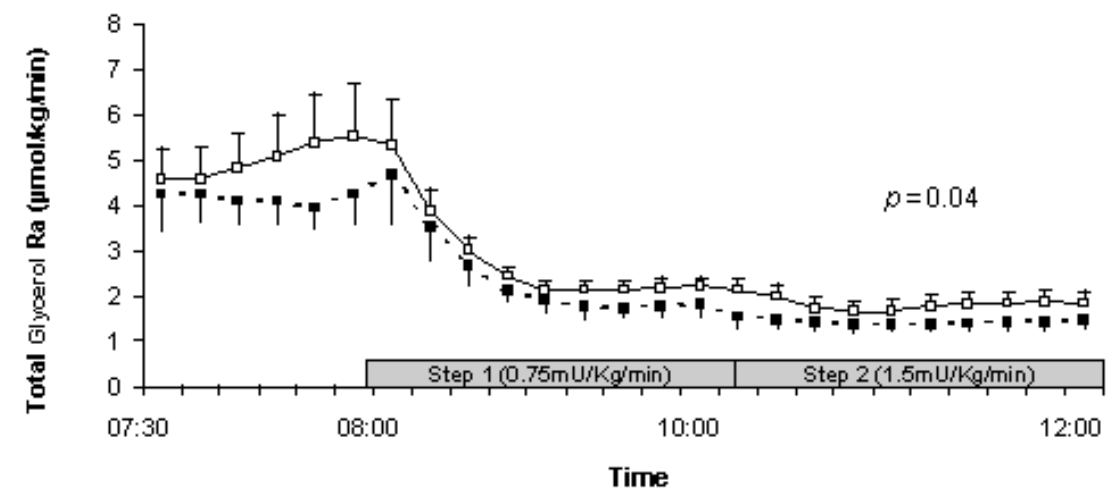

Fig. 4. Effects of B2036-PEG on glycerol turnover. Mean total glycerol $\mathrm{Ra}(\mu \mathrm{mol} / \mathrm{Kg} / \mathrm{min})$ prior to $(07: 30$ to $08: 00 \mathrm{~h})$ and during (08:00 to $12: 00 \mathrm{~h})$ the two-step hyperinsulinaemic clamp at baseline (white squares, solid line) and following 3 weeks of 10 mg B2036-PEG (black squares, broken line). Error bars represent $1 \mathrm{SEM}$

reduced following S10 $(p<0.005)$. Treatment with $\mathrm{S} 10$ led to a significant reduction in glycerol production rate $(p=0.04)$ over the whole study period (07:30 h-12:00 h, Fig. 4), but differences were not detected when each steady state was considered separately (Table 2 ).

Adverse events. No serious adverse events were reported during the study. Of the subjects, two reported local swelling at the injection site, which spontaneously resolved within $2 \mathrm{~h}$.

\section{Discussion}

GH has been implicated in the increased overnight insulin requirements seen in subjects with T1DM during puberty and in the pathogenesis of the dawn phenomenon. Our data support this hypothesis, as 3 weeks' treatment with both 5 and $10 \mathrm{mg}$ B2036-PEG led to reductions in overnight insulin requirements. The extent to which these changes are mediated by suppression of growth hormone's known effects on lipolysis and NEFA production, or by direct effects on peripheral glucose utilisation by muscle, or suppression of hepatic glucose production, remains uncertain. Increased overnight rates of lipolysis in young adults with T1DM, which are not corrected by a preceding period of euglycaemia has been reported, and could be related to increased GH secretion [32]. Studies using the nicotinic acid analogue acipimox, which inhibits lipolysis, leading to reduced plasma NEFA concentrations, have shown enhancement of insulin sensitivity in young, 
non-obese adults with T2DM [33, 34]. A recent study has shown that withdrawal of GH treatment in GH deficient adults results in a decrease in glycerol and NEFA production rate, measured using stable isotopes, and an increase in insulin sensitivity [35]. Use of acipimox to prevent the rise in NEFA following GH administration to $\mathrm{GH}$ deficient subjects prevents a decline in insulin sensitivity following GH administration [36]. Our data support the important role of $\mathrm{GH}$ in regulating lipolysis overnight, as blockade with the higher dose of B2036PEG resulted in reduced NEFA and $\beta O H B$ concentrations overnight and glycerol turnover rate during the clamp study. However, reduction in overnight insulin requirements for euglycaemia were also observed with the $5 \mathrm{mg}$ dose of B2036-PEG, yet NEFA concentrations, $\beta \mathrm{OHB}$ concentrations and glycerol turnover rates were not different from the baseline study.

The observed reductions in insulin requirement for euglycaemia were accompanied by a reduction in plasma insulin concentrations that was non-significant and was not accompanied by a change in insulin clearance. Previously we have reported in adolescents with T1DM that overnight GH concentrations are inversely related to overnight insulin requirements and directly related to insulin clearance [27]. Given that the lower dose of B2036-PEG did not alter overnight NEFA or $\beta O H B$ concentrations, or glycerol production rate, it is possible that there is some direct effect of $\mathrm{GH}$ blockade on hepatic insulin sensitivity.

GH blockade is unlikely to affect overnight insulin requirements through changes in IGF-I as with S5 we observed no change, whereas with $\mathrm{S} 10$, there was a reduction in IGF-I concentrations. Reductions in IGF-I were accompanied by non-significant changes in IGFBP-3 and a reduction in the IGF-I/IGFBP-3 molar ratio, suggesting a possible reduction in free, or bio available IGF-I. Increases, rather than decreases in IGF-I have previously been shown to reduce overnight insulin requirements, both directly [22], and secondary to reductions in GH secretion [37]. Our data suggest that GH blockade has effects on overnight insulin sensitivity that are independent of IGF-I.

The reduction in IGF-I concentrations following GH blockade could be relevant to our failure to observe any changes in insulin sensitivity during the hyperinsulinaemic clamp the following morning. $\mathrm{GH}$ blockade with B2036-PEG is prolonged and has been reported not to cause rebound stimulation of $\mathrm{GH}$ release via the hypothalamic-pituitary axis [23]. GH blockade would have been maintained throughout the clamp period and NEFA were rapidly suppressed by insulin during step 1 of the hyperinsulinaemic clamp on all occasions; yet greater suppression of glycerol turnover following S10 was evident throughout the hyperinsulinaemic clamp. However, despite the greater suppression of glycerol production rate, insulin sensitivity in respect of either hepatic glucose production, or peripheral glucose utilisation remained unchanged.
A limitation of our study is the absence of placebo control data and the possibility that changes in insulin action overnight might be secondary to a non-specific improvement in diabetes control. However this would not explain the lack of effect on insulin sensitivity during the clamp the following morning. The sample size of seven subjects should have provided $80 \%$ power with $5 \%$ significance to detect a $30 \%$ change in endogenous hepatic glucose production during step one of the hyperinsulinaemic clamp. We cannot exclude the possibility that an increase in sample size might permit detection of effects on insulin sensitivity of lesser magnitude.

Persisting IGF-I deficiency, particularly following S10 could explain the absence of change in insulinstimulated glucose disposal during the morning hyperinsulinaemic clamp. Recent studies have shown that variation in free IGF-I concentrations following exogenous administration of rhIGF-I may be an important determinant of insulin sensitivity [38]. Unfortunately, in this study, there was insufficient blood available to allow determination of free IGF-I. Despite reports of decreased type 1 IGF receptor expression in the liver [39], rhIGF-I administration leads to reductions in the hepatic glucose production rate and increased peripheral glucose uptake [37, 40, 41]. The effects of IGF-I on adipose tissue in humans remains unclear, as human adipocytes do not express the type 1 IGF receptor [42]. In vitro studies have shown that incubation of adipocytes with IGF-I stimulates glucose uptake and lipogenesis, but these insulin-like effects are likely to be mediated via the insulin receptor [43]. Thus reduced IGF-I concentrations following S10 could counteract any effects of GH blockade and suppression of lipolysis on insulin sensitivity through direct effects at the liver and via the type 1 IGF receptor in other tissues such as muscle. There might be theoretical disadvantages of reducing IGF-I in Type 1 diabetes in that low concentrations of IGF-I have been associated with microalbuminuria in humans [44]. However, in animal models of diabetes, treatment with a $\mathrm{GH}$ antagonist led to reductions in renal expression of IGF-I and in albumin excretion rates [45].

These data support the importance of overnight $\mathrm{GH}$, lipolysis and NEFA modulation in the pathogenesis of the dawn phenomenon in T1DM. Although they suggest that IGF-I concentrations could be the more relevant determinant of insulin sensitivity the next morning as determined by a hyperinsulinaemic euglycaemic clamp. The therapeutic potential of GH inhibition with B2036-PEG, which is safe and well tolerated, might therefore depend on the relative suppression of IGF-I. In this respect, we observed reductions in overnight insulin requirement with S5, without compromising IGF-I concentrations, although with less effect on lipolysis than observed with S10: data suggesting that doses of B2036-PEG could be titrated in order to achieve optimal glycaemic control. This 
could be of value during adolescence, when glycaemic control can be difficult to achieve.

Acknowledgements. This work was supported by a project grant from the Juvenile Diabetes Research Foundation. R.W. is a Diabetes UK Paediatric Research Fellow. The study drug, B2036-PEG; Pegvisomant (Somavert) was kindly supplied by Pharmacia, Milton Keynes UK. We thank Dr. C. Fox (Northampton General Hospital), Dr. R. Brown and Dr. T. Knight (Stoke Mandeville Hospital, Aylesbury) for their assistance with recruitment. We are extremely grateful to A. Watts, K. Whitehead, M. White, P. Croos and W. Jefferson for technical support, to the subjects who participated in this study and to the staff on the Wellcome Trust Clinical Research Facility, Addenbrooke's Hospital.

\section{References}

1. Edge JA, Dunger DB, Matthews DR, Gilbert JP, Smith CP (1990) Increased overnight growth hormone concentrations in diabetic compared with normal adolescents. J Clin Endocrinol Metab 71:1356-1362

2. Pal BR, Matthews DR, Edge JA, Mullis PE, Hindmarsh PC, Dunger DB (1993) The frequency and amplitude of growth hormone secretory episodes as determined by deconvolution analysis are increased in adolescents with insulin dependent diabetes mellitus and are unaffected by short-term euglycaemia. Clin Endocrinol (Oxf) 38:93-100

3. Catalina PF, Mallo F, Andrade MA, Garcia-Mayor RV, Dieguez C (1998) Growth hormone (GH) response to GHreleasing peptide- 6 in type 1 diabetic patients with exaggerated GH-releasing hormone-stimulated GH secretion. J Clin Endocrinol Metab 83:3663-3667

4. Hansen AP (1970) Abnormal serum growth hormone response to exercise in juvenile diabetics. J Clin Invest 49:1467-1478

5. Krassowski J, Felber JP, Rogala H, Jeske W, Zgliczynski S (1988) Exaggerated growth hormone response to growth hormone-releasing hormone in type I diabetes mellitus. Acta Endocrinol (Copenh) 117:225-229

6. Press, M, Caprio S, Tamborlane WV et al. (1992) Pituitary response to growth hormone-releasing hormone in IDDM. Abnormal responses to insulin and hyperglycemia. Diabetes 41:17-21

7. Speroni G, Ceda GP, Capretti L, Valenti G (1983) Clonidine and GH secretion in insulin dependent diabetes (IDD). Horm Metab Res 15:46-47

8. Merimee TJ, Rabinowtitz D, Fineberg SE (1969) Arginineinitiated release of human growth hormone. Factors modifying the response in normal man. N Engl J Med 280: 1434-1438

9. Dunger DB (1992) Diabetes in puberty. Arch Dis Child 67:569-570

10. Rizza RA, Mandarino, LJ, Gerich JE (1982) Effects of growth hormone on insulin action in man. Mechanisms of insulin resistance, impaired suppression of glucose production, and impaired stimulation of glucose utilization. Diabetes 31:663-669

11. Dunger DB, Edge JA, Pal R, Taylor AM, Holly JM, Matthews DR (1991) Impact of increased growth hormone secretion on carbohydrate metabolism in adolescents with diabetes. Acta Paediatr Scand Suppl 377:69-77

12. Edge JA, Matthews DR, Dunger DB (1990) The dawn phenomenon is related to overnight growth hormone release in adolescent diabetics. Clin Endocrinol (Oxf) 33:729-737
13. Campbell PJ, Bolli GB, Gerich JE (1988) Prevention of the Dawn phenomenon (early morning hyperglycemia) in insulin-dependent diabetes mellitus by bedtime intranasal administration of a long-acting somatostatin analog. Metabolism 37:34-37

14. Kirkegaard C, Norgaard K, Snorgaard O, Bek T, Larsen M, LundAndersen H (1990) Effect of one year continuous subcutaneous infusion of a somatostatin analogue, octreotide, on early retinopathy, metabolic control and thyroid function in Type I (insulin-dependent) diabetes mellitus. Acta Endocrinol (Copenh) 122:766-772

15. Navascues I, Gil J, Pascau C, Senen D, del Pozo E, SerranoRios M (1988) Effect of a long-acting somatostatin derivative SMS 201-995 (sandostatin) on glucose homeostasis in type I diabetes mellitus. Horm Res 29:92-94

16. Orskov L, Moller N, Bak JF, Porksen N, Schmit O (1996) Effects of the somatostatin analog, octreotide, on glucose metabolism and insulin sensitivity in insulin-dependent diabetes mellitus. Metabolism 45:211-217

17. Atiea JA, Aslan SM, Owens DR, Luzio S (1990) Early morning hyperglycaemia "dawn phenomenon" in non-insulin dependent diabetes mellitus (NIDDM): effects of cortisol suppression by metyrapone. Diabetes Res 14:181-185

18. Martina V, Maccario M, Tagliabue M, Corno M, Camann F (1989) Chronic treatment with pirenzepine decreases growth hormone secretion in insulin-dependent diabetes mellitus. J Clin Endocrinol Metab 68:392-396

19. Dunger DB, Acerini CL (1997) Does recombinant human insulin-like growth factor-1 have a role in the treatment of diabetes? Diabet Med 14:723-731

20. Acerini CL, Patton CM, Savage MO, Kernell A, Westphal O, Dunger DB (1997) Randomised placebo-controlled trial of human recombinant insulin-like growth factor I plus intensive insulin therapy in adolescents with insulin-dependent diabetes mellitus. Lancet 350:1199-1204

21. Cheetham TD, Holly JM, Clayton K, Cwyfan-Hughes S, Dunger DB (1995) The effects of repeated daily recombinant human insulin-like growth factor I administration in adolescents with type 1 diabetes. Diabet Med 12:885-892

22. Crowne EC, Samra JS, Cheetham T, Watts A, Holly JM, Dunger DB (1998) Recombinant human insulin-like growth factor-I abolishes changes in insulin requirements consequent upon growth hormone pulsatility in young adults with type I diabetes mellitus. Metabolism 47:3138

23. Thorner MO, Strasburger CJ, Wu Z et al. (1999) Growth hormone $(\mathrm{GH})$ receptor blockade with a PEG-modified GH (B2036-PEG) lowers serum insulin-like growth factor-I but does not acutely stimulate serum GH. J Clin Endocrinol Metab 84:2098-2103

24. Shojaee-Moradie F, Jackson NC, Jones RH, Mallet AI, Hovorka R, Umpleby AM (1996) Quantitative measurement of 3-O-methyl-D-glucose by gas chromatographymass spectrometry as a measure of glucose transport in vivo. J Mass Spectrom 31:961-966

25. Wolfe R (1992) Radioactive and stable isotope tracers in biomedicine: principles and practice of kinetic analysis, 1st edn. Wiley-Liss, New York

26. Elia M, Kahn K, Calder G, Kurpad A (1993) Glycerol exchange across the human forearm assessed by a combination of tracer and arteriovenous exchange techniques. Clin Sci (Lond) 84:99-104

27. Acerini CL, Cheetham TD, Edge JA, Dunger DB (2000) Both insulin sensitivity and insulin clearance in children and young adults with type I (insulin-dependent) diabetes vary with growth hormone concentrations and with age. Diabetologia 43:61-68 
28. De Bodo RC, Steele R, Altszuler N, Dunn A, Bishop JS (1963) On the hormonal regulation of carbohydrate metabolism studies with $\mathrm{C} 14$ glucose. Recent Prog Horm Res 19:445-482

29. Steele R (1959) Influence of glucose loading and injected insulin on hepatic glucose output. Ann NY Acad Sci 82: 420-430

30. Romijn JA, Coyle EF, Sidossis LS et al. (1993) Regulation of endogenous fat and carbohydrate metabolism in relation to exercise intensity and duration. Am J Physiol 265: E380-E391

31. Mari A (1992) Estimation of the rate of appearance in the non-steady state with a two-compartment model. Am J Physiol 263:E400-E415

32. Hagstrom-Toft E, Bolinder J, Ungerstedt U, Arner P (1997) A circadian rhythm in lipid mobilization which is altered in IDDM. Diabetologia 40:1070-1078

33. Fulcher GR, Catalano C, Walker M et al. (1992) A double blind study of the effect of acipimox on serum lipids, blood glucose control and insulin action in non-obese patients with type 2 diabetes mellitus. Diabet Med 9:908-914

34. Walker M, Agius L, Orskov H, Alberti KG (1993) Peripheral and hepatic insulin sensitivity in non-insulin-dependent diabetes mellitus: effect of nonesterified fatty acids. Metabolism 42:601-608

35. Gibney J, Healy ML, Stolinski M et al. (2003) Effect of Growth Hormone $(\mathrm{GH})$ on Glycerol and Free Fatty Acid Metabolism during Exhaustive Exercise in GH-Deficient Adults. J Clin Endocrinol Metab 88:1792-1797

36. Nielsen S, Moller N, Christiansen JS, Jorgensen JO (2001) Pharmacological antilipolysis restores insulin sensitivity during growth hormone exposure. Diabetes 50:23012308

37. Acerini CL, Harris DA, Matyka KA et al. (1998) Effects of low-dose recombinant human insulin-like growth factor-I on insulin sensitivity, growth hormone and glucagon levels in young adults with insulin-dependent diabetes mellitus. Metabolism 47:1481-1489
38. Frystyk J, Hussain M, Skjaerbaek C et al. (1997) Serum free IGF-I during a hyperinsulinemic clamp following 3 days of administration of IGF-I vs. saline. Am J Physiol Endocrinol Metab 273:E507-E513

39. Caro JF, Poulos J, Ittoop O, Pories WJ, Flickinger EG, Sinha MK (1988) Insulin-like growth factor I binding in hepatocytes from human liver, human hepatoma, and normal, regenerating, and fetal rat liver. J Clin Invest 81:976981

40. Carroll PV, Christ ER, Umpleby AM et al. (2000) IGF-I treatment in adults with type 1 diabetes: effects on glucose and protein metabolism in the fasting state and during a hyperinsulinemic-euglycemic amino acid clamp. Diabetes 49:789-796

41. Cusi K, DeFronzo R (2000) Recombinant human insulinlike growth factor I treatment for 1 week improves metabolic control in type 2 diabetes by ameliorating hepatic and muscle insulin resistance. J Clin Endocrinol Metab 85: 3077-3084

42. Frick F, Oscarsson J, Vikman-Adolfsson K, Ottosson M, Yoshida N, Eden S (2000) Different effects of IGF-I on insulin-stimulated glucose uptake in adipose tissue and skeletal muscle. Am J Physiol Endocrinol Metab 278:E729E737

43. Siddals KW, Westwood M, Gibson JM, White A (2002) IGF-binding protein-1 inhibits IGF effects on adipocyte function: implications for insulin-like actions at the adipocyte. J Endocrinol 174:289-297

44. Amin R, Schultz C, Ong K et al. (2003) Low IGF-I and elevated testosterone during puberty in subjects with type 1 diabetes developing microalbuminuria in comparison to normoalbuminuric control subjects: the Oxford Regional Prospective Study. Diabetes Care 26:1456-1461

45. Flyvbjerg A, Bennett WF, Rasch R, Kopchick JJ, Scarlett JA (1999) Inhibitory effect of a growth hormone receptor antagonist (G120K-PEG) on renal enlargement, glomerular hypertrophy, and urinary albumin excretion in experimental diabetes in mice. Diabetes 48:377-382 